Revista de la red interuniversitaria de estudios sobre las literaturas rioplatenses contemporáneas en Francia

Hors-série | 2019

Ricardo Piglia: Cierta idea de literatura

\title{
La némesis literaria de Emilio Renzi en sus Diarios (de Ricardo Piglia)
}

Daniel Mesa Gancedo

\section{OpenEdition}

Journals

Edición electrónica

URL: http://journals.openedition.org/lirico/7934

DOI: $10.4000 /$ lirico.7934

ISSN: 2262-8339

Editor

Réseau interuniversitaire d'étude des littératures contemporaines du Río de la Plata

\section{Referencia electrónica}

Daniel Mesa Gancedo, «La némesis literaria de Emilio Renzi en sus Diarios (de Ricardo Piglia) », Cuadernos LIRICO [En línea], Hors-série | 2019, Puesto en línea el 27 febrero 2019, consultado el 09 mayo 2019. URL : http://journals.openedition.org/lirico/7934 ; DOI : 10.4000/lirico.7934

Este documento fue generado automáticamente el 9 mayo 2019.

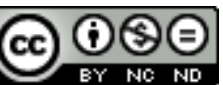

Cuadernos LIRICO está distribuido bajo una Licencia Creative Commons Atribución-NoComercialSinDerivar 4.0 Internacional. 


\title{
La némesis literaria de Emilio Renzi en sus Diarios (de Ricardo Piglia)
}

\author{
Daniel Mesa Gancedo
}

Los diarios de Emilio Renzi exhiben el proceso de construcción de un sujeto literario, sin dejar de lado ninguno de sus avatares. En las páginas que siguen me ocuparé tan sólo de uno de los mecanismos más evidentemente denotativos de ese proceso: el dibujo del que podríamos considerar perfil externo de la figura del autor, esto es, la aparición de una Gestalt, sobre o (con más propiedad en este caso) contra el fondo de otras figuras de escritores. El Renzi que revelan estos Diarios es, pues, una contrafigura que define su contorno en el antagonismo y la rivalidad, y por eso me atreveré a postular que alguno de esos otros sujetos cobra el valor de némesis, en el sentido difuso en el que lo viene usando cierto género de la narrativa popular contemporánea: si el yo literario fuera el superhéroe -enmascarado, desde luego- de este relato, su némesis se define como un contrincante que se le parece, que conoce sus poderes, por compartir un pasado común y experiencias fundantes que no pueden echarse en el olvido.

\section{Los años de hostilidad}

2 Desde hace tiempo sabemos que para Piglia "la conciencia que narra es una conciencia paranoica" (1991) y que esa idea le servía para definir "la situación de la novela contemporánea". Sabemos ahora que los Diarios son la puesta en escena más espectacular de esa conciencia y el intento más radical de Piglia por construir esa "novela contemporánea". En una página de esos Diarios fechada el martes 22 de noviembre de 1977, hay una anotación que se refiere al origen del género novelesco en Argentina: “ Novela argentina. Por supuesto, el carácter nacional del género surge en la autobiografía. Los "retratos" de la gente que el autor trata y conoce empiezan a definir un uso novelístico de la narrativa personal" (Piglia 2017: III, 49) ${ }^{1}$. Mediado el primer volumen de los Diarios aparece un retrato grupal, que podría leerse como alegoría de los Diarios como novela de origen: 
El departamento era amplio y luminoso y estaba lleno de libros. No había cuadros en las paredes, si bien en el piso del pasillo, apoyada contra la pared, se veía una pintura de su amigo Freddy Martínez Howard, un retrato grupal, compuesto a la manera de un cuadro holandés del siglo XVI, donde se podía identificar a Emilio, a Beba Eguía, a León Rozitchner y a su compañera Claudia, y en un costado de la tela se veía a Gerardo Gandini, lívido, con una semisonrisa, sosteniendo en la mano una rosa roja. Todos rodeaban una mesa en cuyo centro resplandecía un trozo de carne roja, una suerte de naturaleza muerta, muy argentina. [...] Una tarde Freddy había pintado el cuadro y se lo había regalado a Gerardo a cambio de que el músico le escribiera una sonata, la sonata Howard. Dicho y hecho, Gandini escribió la sonata en una noche y se la cambió por el cuadro, que al final fue a parar a manos de León, que no pudo soportar la imagen de su cara (de boludo, como decía el filósofo) y resignado se lo pasó a Renzi, que lo puso en el piso de su estudio. ("En el estudio"; I, $121)^{2}$.

3 Escritores, artistas, músicos, mujeres: serán los protagonistas de esa refacción "muy argentina", que -como el cuadro que circula de amigo a amigo y encuentra difícil acomodo- también son estos Diarios. Pero antes de avanzar en la descripción de esa "gente que el autor trata", conviene recordar que la conciencia paranoica, tal como la definía Piglia en 1991, es, propiamente, la que caracteriza al sujeto de estos Diarios: su ser (como) escritor -previo incluso a su escritura ${ }^{3}$ - depende de su capacidad de sortear las amenazas de otros escritores, muy parecidos a él, que obstaculizan el camino al objetivo. Los Diarios son pródigos en testimonios de esa conciencia amenazada por un entorno hostil, que conmina al refugio y a la automarginación, empezando incluso por los referentes formativos:

Lo que quiero hacer lo aprendo de los escritores imaginarios. Por ejemplo, Stephen Dedalus o Nick Adams. Leo sus vidas como forma de entender de qué se trata. No me interesa inspirarme en los escritores "reales". (Lunes, 1960; I, 60)

4 La figura del "escritor imaginario" irá más allá de la mera designación denotativa (escritores ficticios, protagonistas de textos de ficción) y llega a definir la propia estrategia enunciativa de -ahora sí- Piglia al componer estos Diarios como ficción formativa (antes incluso que como "novela de formación"): para dar su propia lección, Piglia se reconstruye en la figura de Renzi, otro escritor imaginario. Puede así reconstruir el espacio (por tanto, también imaginario) en el que ese escritor se mueve como un espacio de confrontación y lucha, mediante un relato en el que, antes o después, hará su aparición una figura concreta que se revestirá de los rasgos de la némesis en el sentido en el que se ha definido en el primer párrafo de este trabajo.

5 La construcción de ese espacio de soterrada hostilidad que define el campo en el que comienza su andadura el escritor Renzi encuentra un anclaje intertextual muy interesante en las páginas de apertura de los Diarios. Allí, confiesa estar leyendo -entre otros libros- The Opposing Self, de Lionel Trilling (I, 17), recopilación de nueve ensayos que persiguen el desarrollo del "yo antagónico"4 característico de la modernidad. Hasta tal punto es importante en los Diarios esta imagen, que podría entenderse como una de las claves que definen explícitamente su extensión. No es preciso avanzar mucho en la lectura del libro de Trilling para encontrar el rasgo que, a su juicio, da unidad al yo moderno: “[...] Hay una característica distintiva que me parece eminentemente importante: su intenso y adverso imaginario de la cultura en la cual cobra existencia" ${ }^{5}$ (Trilling 1955: X, mi traducción). En la mitad casi exacta del tercer volumen de los Diarios hay una anotación que parecería responder a Trilling y marcar, así, uno de los múltiples finales posibles de la modernidad (y, significativamente, también de los Diarios): 
[...] todos habían vuelto al redil, todos ahora eran escritores oficiales, reconocidos, recibían premios y eran entrevistados en la televisión y firmaban columnas de opinión en los grandes diarios y sus fotos aparecían frecuentemente en revistas y periódicos. Los escritores eran ahora, volvió a subrayar enfurecido, decorativos y eran recibidos en los salones, en las embajadas, viajaban de un lado al otro, daban charlas y eran insignificantes pero bien considerados [...]. Así las cosas, Emilio había percibido con claridad que una época había terminado y que una cultura había sido derrotada. Antes, pensaba Renzi, podíamos circular en los márgenes ligados a la contracultura, al mundo subterráneo del arte y la literatura, peroahora todos éramos figuritas de un escenario empobrecido y debíamos jugar el juego que dominaba el mundo. No había esperanza ni voluntad ni coraje para cambiar las cosas o, al menos, para correr el riesgo de vivir de ilusiones. Por eso había pensado que esa temporada de su vida había terminado y que los veinticinco años dedicados a convertirse en un escritor estaban concluidos. Y lo que venía después era previsible y mundano y no formaba parte de la historia de la formación de su espíritu personal. ("Un día en la vida"; III, 160)

El yo antagónico moderno se ha convertido en un yo domesticado postmoderno. Terminada la dictadura, recuperada la democracia, ha terminado el tipo de cultura en el que -contra el que- Renzi había sabido definirse. Es entonces cuando terminan, de verdad, sus “años de formación”, más allá de la década que recogía el volumen I -así subtituladode los Diarios. Esa "formación del espíritu personal" ha abarcado la no menos simbólica duración de cinco lustros ${ }^{6}$. Cuando terminan esos años de hostilidad, cuando se disuelve el "yo antagónico", cuando sospecha que ya no va a encontrar enemigo a su altura, Renzi decide clausurar aparentemente sus Diarios, aunque sea a mitad de un volumen.

7 Pero hasta entonces, los Diarios han sido un sostenido cuaderno de batalla, o si se prefiere una agenda paranoica. "También los paranoicos tienen enemigos", dijo Renzi que le dijo su padre, en el relato que inauguraba Prisión perpetua ("En otro país"; Piglia 2000: 13)7. La misma percepción de la realidad literaria marca la preparación de la salida al público del aprendiz de escritor:

No termino de entender contra qué lucho, imagino enemigos múltiples y los enfrento uno por uno como en un duelo. Es imposible pelear con todos a la vez porque tengo que pelear también conmigo mismo. Todo es sencillo, dijo, si se comprende que nunca hay que bajar los sistemas de defensa. Hay que estar en guardia, dijo, lo demás es ilusorio. (Sábado 7 [/mayo/], 1966; I, 247)

8 Renzi será un perpetuo duelista (como los célebres personajes de Conrad), de rasgos quijotescos, y cuando su propósito de ser un escritor empiece a encontrar apoyo en textos publicados, la sensación de hostilidad y amenaza no hará sino reforzarse:

Los que me han conocido antes parecen no perdonarme el hecho de haber realizado lo que he deseado -digamos así-. De allí cierto rencor y cierta agresividad que percibo en los viejos amigos, que me ven distinto a como ellos me habían imaginado. Los que me conocen ahora ven sólo en mi vida lo que hago como una virtud y no como una sorpresa que los llena de inquietud, ante un desconocido que sigue siendo sin embargo, para ellos, "familiar". (Domingo, [/marzo/] 1967; I, 296-297)

9 Renzi es consciente de que la amenaza procede de su círculo más estrecho, porque es ahí donde se encuentran los sujetos que comparten su pasado común y sus experiencias de origen, es ahí donde duerme la razón de la envidia o la ofensa o la deuda, reales o imaginarias. El sujeto, transformado ya en héroe literario, parece pretender escapar a esas obligaciones y se vuelve siniestro (en el sentido estrictamente freudiano): protagonista de una "inquietante familiaridad", para los que saben quién fue antes de ser 
quien es. Y él, que antes fue, probablemente, envidioso de otros escritores (más o menos imaginarios), ahora se sabe envidiado $\mathrm{y}$, por tanto, en peligro.

La sensación se incrementa con el cambio de década, a raíz de un episodio al que Renzi otorga una significación capital en su biografía: la "operación rastrillo" por parte del ejército el 14 de enero de 1972, que le obliga a abandonar su apartamento y a vivir durante un tiempo prácticamente escondido (“En el bar"; II, 9) . En este caso, la amenaza trasciende el círculo literario de Renzi (aunque se origine, sin duda, en sus actividades, que mezclan literatura y política), pero cuando anota esa experiencia la traduce en términos ficcionales o alegóricos, que pueden extenderse retrospectivamente para dar sentido a su historia:

Vivo como alguien que cumple una misión delicada y secreta en un país extranjero. Desconocido, perdido entre la gente, sin esperar nada de nadie, aprendiendo a sobrevivir con sus propios recursos, sin contacto con el país que le ha encargado la misión y con el único objetivo de cumplir un plan que conoce sólo a medias. La vida de un espía infiltrado en territorio enemigo. Ésa ha sido mi identidad -o mi certeza en el mundo- desde el comienzo, los signos están en estos cuadernos, escritos en un lenguaje cifrado cuyo sentido real sólo yo puedo entender. (Miércoles 12 [/julio/ ], 1972; II, 312)

11 Es como si desde el origen, Renzi hubiera estado preparándose para su vida clandestina, entrenándose para sobrevivir en un entorno hostili'. La escritura del diario puede servir ahora como libro de claves para, una vez más, escapar del asedio.

Las circunstancias políticas de los años subsiguientes no harán sino agravar esa sensación subjetiva. Desde abril de 1976, pocos días después del golpe militar, Renzi tiene la impresión de "vivir históricamente" (Viernes 9 de abril, 1976; III, 24), con "temores que van más allá de los vaivenes del alma". Apenas un mes después (Jueves 6 de mayo, 1976; III, 25), anota su nostalgia de "escribir tranquilo sin temer a la historia". Medita sobre la posibilidad de exiliarse, pues "por primera vez las crisis son objetivas", y concluye con la misma metáfora que había usado en 1972: "Lo he perdido todo, vivo en territorio enemigo, hundido en la sucia contemplación" (Lunes 30 [/agosto/], 1976; III, 29). Como se sabe, ésas son las circunstancias en que se está escribiendo Respiración artificial, casi como un modo de huir de la pesadilla. Cuando la novela sale a la luz, a finales de 1980, y comienza a tener éxito, confirmando a su autor como escritor con un destino logrado, la sensación de hostilidad no disminuye; sólo se desplaza o, por mejor decir, vuelve al ámbito original: el literario. A mitad de agosto de 1981, las referencias son explícitas:

[...] me despierta una llamada de Antoine Berman desde París; el interés de él por mi novela compensa la dificultad con el ambiente literario de por acá. [...] Es tan hostil el ambiente aquí y tan difícil ganarse la vida en Buenos Aires que la posibilidad de trabajar en la academia [estadounidense] aparece como una salida posible. (Martes 11 [/agosto/], 1981; III, 148)

13 Y un par de días más tarde responsabiliza directamente a la novela de haberle creado "un espacio social que no [le] gusta" (Jueves 13 [/agosto/], 1981; III, 149). El texto que constituye su primera novela, su primer gran logro como escritor de ficción, parece haberlo convertido en una especie de adalid de la crítica contra la dictadura. Pero ése no es el duelo que Renzi quería sostener: la repercusión y la lectura que la novela recibe vincula a su autor con personajes que no considera afines y lo enfrenta a enemigos que no considera a su altura ${ }^{10}$.

14 Seguramente, la inmediata deriva posterior de la historia, su cruce con la vida y con la literatura, desvirtúa -en la percepción de Renzi- el antagonismo que definía su proyecto 
literario, tal como va surgiendo en los Diarios. De ahí que, poco a poco, sienta la necesidad de ir clausurando esa etapa y resguardando al "yo opositivo" que hizo germinar ese ser escritor en una convicción más profunda, la de que la literatura es, primordialmente, un espacio de confrontación entre escritor y lector, algo ya expresado tempranamente:

Cuando trabajo no puedo leer. Nada me interesa o todo parece ligado a lo que estoy escribiendo. Los libros caen atrapados por la pasión de la novela y se convierten en objetos superfluos o en objetos contagiosos. No valen nada o dicen mejor lo que yo no puedo terminar de escribir. Curiosa situación, el escritor como enemigo del lector. Uno está tan sensibilizado por el lenguaje que todo lo que está escrito le parece personal o personalmente dirigido. (Sábado [/14 de septiembre/], 1968; II, 60)

El delirio interpretativo es, junto con la amenaza, el otro componente del complejo paranoide (Piglia 1991). Para el escritor eso no puede significar sino que todo lo que lee le está "personalmente dirigido". A fortiori, todos los libros del mundo dicen ya aquello que él, mientras lee, se esfuerza en escribir: el escritor es la némesis del lector; el Escritor es la némesis de Renzi ${ }^{11}$, el supervillano que amenaza el logro de su misión. Los otros escritores son apenas avatares de esa némesis, figuras que asedian su propio proyecto.

\section{Los diarios de serie B}

En dos anotaciones de la segunda mitad de 1965 Renzi establece un vínculo directo entre amistad y enemistad, dos caras de la misma relación, pareja paradójica que reproduce la tensión antagónica que define mi lectura. El primero de esos dos lugares es una cita (no enteramente identificada) que reza textualmente: ""Hay amistades extrañas, hay amigos que casi se quieren matar el uno al otro, toda la vida se la pasan así, sin que a pesar de ello se puedan separar. Separarse es imposible". Dostoyevski" (Domingo [/agosto/], 1965; I, 196) ${ }^{12}$. Unos meses más tarde parece traducir y sintetizar la idea, aplicada a su propia experiencia: "Es notable experimentar el choque entre la conciencia que yo tengo de mí mismo y el modo en que los otros me ven. [...] La mirada enemiga sólo se da entre amigos" (Martes 14 [/diciembre/], 1965; I, 209). Ambas citas reproducen otra variante de la noción de lo siniestro, entendida como lo inquietantemente familiar: el desdén del amigo, como el aprecio por parte del enemigo, resultan afectos extraños, pero definen las tensiones que sostienen particularmente el mundo literario, tal como Renzi lo experimenta y lo imagina $^{13}$.

Cuando Renzi teoriza a posteriori sobre su nuevo modo de escribir autobiografía siguiendo series de acontecimientos repetidos, una de las primeras y de las más recurrentes a lo largo del diario es la "serie de los amigos", identificada en el volumen II (pero sólo entre 1968 y 1971) como "Serie B". Aunque nunca se especifica la motivación de la letra que designa a las diferentes series ${ }^{14}$, en este caso podría relacionarse con el bar, el lugar privilegiado para los encuentros con esos amigos, pero me parece que no sería descabellado sugerir que esa insistencia en una trama de relaciones sostenida en afectos paradójicos y que genera conflictos a veces melodramáticos podría hacernos leer cinematográficamente- unos diarios de "serie B" en esas secuencias unidas -como muchas de las películas de ese tipo- por un personaje recurrente (Renzi), cuya vida parece reducirse entonces a atrezzo o punto de intersección de vidas ajenas ${ }^{15}$.

A pesar del aparente interés inicial de Renzi sólo por "escritores imaginarios", lo cierto es que los Diarios son riquísimos en la definición de un retrato grupal en el que el personaje 
va a encontrar difícil acomodo. En ese retrato, el fondo más difuso lo configuran escritores reales canonizados más allá del campo estrictamente argentino, todavía muy productivos cuando el aprendiz de escritor inicia su carrera: los escritores del boom con los que Renzi, de vez en cuando se cruza, y mide armas dialécticas ${ }^{16}$.

Pero a mis efectos resulta más relevante la nómina de escritores reales que constituyen la verdadera red de "amistades extrañas" de Renzi, el friso de "retratos de la gente que el autor trata" y que así convierte a los Diarios -recuérdese- en un importantísimo capítulo de la "novela argentina". El primero que hay que retener es el filósofo José Sazbón, amigo de los más antiguos y duraderos, "el más cercano" en 1960 (Viernes 10 [/junio/]; I, 79) y ya "otro" en 1972: "Beca de doctorado en París, carrera de investigador asegurada, etc., libre para estudiar toda su vida. Por contraste, me veo a mí mismo en el aire, sin futuro" ([/febrero/]; II, 290). Unos años más tarde, será el primer lector de Respiración artificial, pero ya superado por Renzi:

[...] Es el primero que ha leído Respiración artificial, si lo que escribo pasa por la ardua aduana de José no me importa lo que digan los demás. Igual, hay ciertas tensiones con él [...], demasiado atado a Borges, a su retórica, y también a la moda (por ejemplo, la historia es ficción). Piensa como novedad lo que yo creía hace diez años. (Jueves 14 [/agosto/], 1980; III, 125)

Sin embargo, cuando Sazbón escribe su reseña sobre la novela, esa distancia se convierte en decepción: "La lectura que no busco, una interpretación excesiva de lo que en la novela es alusivo y deliberadamente críptico" (Sábado 14 de febrero, 1981; III, 139). Unos meses después, en la última aparición de Sazbón en los Diarios, el distanciamiento intelectual resulta inequívoco: "Aire kafkiano, delirio teórico, excesivamente interesado en el estructuralismo" (Viernes 7 de agosto, 1981; III, 147).

Al lado de esa figura germinal contra la que Renzi se define durante más de dos décadas, hay otra tejida con "amigos más cercanos" "en cuya literatura confío tanto como en la mía" (Jueves 9 [/marzo/], 1967; I, 295): son amigos como Jorge ("Dipi”) di Paola, Miguel Briante, Juan José Saer o León Rozitchner. Este último -antes de aparecer en el retrato grupal emblemático que se citó antes- era visto "como una sombra de lo que quizá yo vaya a ser en el futuro" (Domingo 31 de diciembre, 1972; II, 332) y más tarde "como un espejo futuro de mí mismo" (Martes 2 [/abril/], 1974; II, 352). A diferencia de Sazbón -una especie de "yo retardatario"-, ahora el amigo es una especie de "doble por anticipación", y ese esquema dinámico seguirá reproduciéndose frente a otros: Héctor ("Toto") Schmucler, por ejemplo, "una de esas amistades típicas de mi vida", introduce en el retrato una deriva edípica que resultará muy relevante: "soy el padre, el "maduro", y el otro se lleva todo de mí, que sigo inmóvil" (Viernes 1 de diciembre, 1972; II, 323) ${ }^{17}$.

Pero, sin duda, de entre los proyectos literarios de sus contemporáneos en trance de consagración, el que más le interesa a Renzi es el de Manuel Puig. Desde muy temprano se le ofrece como escritor modélico: "novelista profesional, el primero que conozco y está decidido a vivir de su literatura. [...] Entonces uno lo ve y no parece un escritor, y ése es su mérito porque es más escritor que cualquiera de los farsantes que representan ese papel, [...]" (Viernes 25 de abril, 1969; II, 136). La admiración pronto parece traslucir una cierta envidia: "Muy sagaz, con una fina conciencia profesional y un gran sentido para detectar "qué" es una buena escritura: [...]. Su cultura es muy instrumental, como debe ser la formación de un escritor: tiene una gran capacidad para encontrar rápidamente lo que necesita" (Viernes 16 [/julio/], 1971; II, 259). Al cabo de pocos meses ya es explícito: "[es] otro de mis "dobles de cuerpo" (como se dice en el cine de los actores anónimos que suplantan a las estrellas en las escenas de riesgo, ponen el cuerpo pero nadie los 
reconoce), y me provoca hondas cavilaciones y envidias" (Martes 21 de septiembre, 1971; II, 271). La envidia, la sustancia que define u origina la némesis, encuentra quizá por primera vez un objeto-escritor "no imaginario", al punto de que quiere asumirlo como sujeto sustitutivo o experimental ${ }^{18}$.

21 Osvaldo Lamborghini es un caso también singular e importante desde el punto de vista que me interesa: Renzi (o Piglia) parece haber querido convertirlo explícitamente en un escritor imaginario ${ }^{19}$, que no queda demasiado bien parado. No obstante, a finales de los sesenta, confesaba mantener con él "una relación irónica basada en un buen nivel de acuerdo intelectual", aunque le "aburren la afectación y las insistencias cómplices que no llevan a ningún lado" ([Martes] 25 de noviembre, 1969; II, 166). Será bastante después, cuando los proyectos literarios de ambos empiecen a cuajar, cuando la relación se defina en términos de antagonismo: "Me dice, con su tono conspirativo, que Gabriela Massuh le ha pedido una nota sobre [Jorge] Asís y sobre mí, todos nos oponen, según parece, como líneas enfrentadas de la literatura actual. Pero en realidad, me dice con su tonito perverso, tendría que escribir sobre vos y yo" (Miércoles [6/mayo/], 1981; III, 142). Desplazar el objeto de la rivalidad -despreciando al tercero- y atribuir en este caso la conciencia antagónica a Lamborghini, contribuye a la tensión dramática de la escena, como si el rival lanzase un reto, como si emplazase a un duelo, sin saber -irónicamenteque ya Renzi había desarrollado ficcionalmente ese duelo en su novela. Para terminar de definir la soterrada enemistad, decantar las afinidades y la construcción del campo de batalla, Renzi aclara que Lamborghini está "ligado a la revista Vigencia, que hace la política cultural de la dictadura" ${ }^{20}$.

Otras figuras más desdibujadas ${ }^{21}$ contribuirán a definir la estructura contradictoria, opositiva, del mundo de relaciones literarias de Renzi, pero sólo retendré uno de esos nombres semiocultos ${ }^{22}$, porque protagoniza una escena patética que lleva a su extremo la comprensión del espacio literario como un campo de batalla regido por la némesis:

Osvaldo B. [...] delata y cita por teléfono a la gente. [...] "Hago esto", dice, "porque Roberto me frustró la carrera literaria." [...] El estúpido narcisismo de los escritores era patético e infatuado en él. Ya se ve que se guardó el odio y el resentimiento durante años, y luego delató y mandó a la muerte a toda la dirección política. No se lo puede juzgar porque no se puede decir nada sobre alguien que ha sido torturado. De todas maneras, su "explicación" es un ejemplo de la retórica del escritor maldito que hace de la canallada una poética y un designio. [...] Podría estar en la serie siniestra de los escritores imaginarios, también su mezquindad se parece a la atmósfera que circula en estos días entre "nosotros". (Jueves 6 [/agosto/], 1981; III, 145-146)

Cuando la dictadura todavía no ha terminado, encuentra Renzi un ejemplo de autor que ha llevado a la vida sus rencores literarios. Esa figura es, verdaderamente, la némesis que emerge del pasado de los escritores para encontrar una supuesta justicia. El escritor, cualquier escritor, podría ser víctima de un homólogo que ha encontrado el camino para realizar "el estúpido narcisismo de los escritores", hasta el punto de ser capaz de aniquilar a aquellos que se interpusieron en su camino.

\section{La serie "V": David Viñas}

Si bien ese personaje infame y ominoso podría cerrar, con la ominosa "B" de su apellido, la serie así designada, conviene, sin embargo, ampliar el alfabeto hasta la "V" para encontrarse con el más antagónico de los sujetos contra los que Renzi se figura: David 
Viñas. Justo después de pensar en la "serie B", la de los encuentros con amigos, como la primera que se le ocurre para reconstruir su diario, Renzi afirma que no tendría por qué ser tan "ambicioso" y podría limitarse a "los encuentros con una sola persona". Y, entonces, el primer nombre que menciona es el de David Viñas: “¿cuántas veces aparecía David Viñas en su diario?, ¿de qué hablaban, qué se decían, por qué se peleaban?” (II, 13).

La primera aparición de ese nombre es especialmente significativa por lo que tiene de índice genealógico. A finales de 1964, reflexionando sobre la proyección del peronismo en la literatura, Renzi lo asocia a autores viejos: "Escritores como Beatriz Guido, Sábato y el mismo Viñas ven al peronismo como un continuo y cotidiano apocalipsis, parece que el país se hubiera subido a un escenario donde sólo hay representación y falsedad" (Lunes 7 [/diciembre/], 1964; I, 151). En Renzi (como en Piglia), toda mención del peronismo está asociada -como es sabido- a la figura del padre, cuya paranoia parece desencadenarse con la caída del régimen en 1955. Viñas aparece como uno de los intelectuales que empiezan a cuestionar la ficcionalidad del peronismo y es, por tanto, una contrafigura paterna, tensión edípica casi demasiado evidente que marcará toda la relación.

No faltan detalles físicos en la descripción de esta figura, pero retendré sólo un lugar en el que Renzi ironiza sobre el aspecto, en relación con la literatura de Viñas, tan distinta de la suya: "Ser otro, David no puede y termina sirviendo de partenaire al personaje público que se ha inventado. David, le digo, afeitate los bigotes y cambiá de zona, así vas a encontrar caminos nuevos para tu literatura" (Viernes 4 [/septiembre/], 1970; II, 215).

Desde el punto de vista moral, uno de los principales rasgos de Viñas es el subjetivismo aparentemente veleidoso, que se combina con una extraordinaria inteligencia autoconsciente, en la que Renzi reconoce un rasgo compartido: “Al fin de la tarde cayó David, con su habitual neurosis de los días feriados [...] exagera su inteligencia para armar coartadas (como todos nosotros)" ([Viernes] 1 de mayo, 1970; II, 180). Se va componiendo así la imagen de una personalidad casi bipolar (inteligente y arbitrario; eufórico y angustiado; generoso y egocéntrico), algo grotesca, que apenas necesita a su interlocutor (y quizá por eso lo fascina). Sea como sea, Viñas presenta a ojos de Renzi una concepción agonística de la vida y la literatura, que consuena con su propia visión hostil y paranoica. Unas palabras del 1 de mayo de 1970 podrían estar hablando de cualquiera de los dos: "[...] se siente solo, desvalorizado, arremete contra molinos de viento siempre renovados y confunde al escritor con un boxeador, siempre atento al ranking, siempre en "la noticia"" (II, 180). Lo mismo ocurre al año siguiente, cuando se define a Viñas como alguien que lucha contra "rivales fantasmáticos que se renuevan sin salir del círculo amenazador que, según él, lo condena al olvido" (Lunes 13 [/septiembre/], 1971; II, 267). Renzi, sin decirlo nunca directamente -a diferencia del caso de Puig, por ejemplo- parece haber encontrado en Viñas otro de esos "dobles de cuerpo" en los que experimenta sus propios temores. Es significativo que un poco más tarde le reconozca como "su mayor talento", la capacidad de "reconstruir su vida" después de cada crisis: "se destruye, vende todo, queda solo en el mundo, vive en hoteles baratos, está perdido en la ciudad sin plata y, de golpe, unos días después vuelve a instalarse en una casa con sus libros" (Jueves 30 [/diciembre/], 1971; II, 285). Hay en Viñas un modelo heroico, del que quizás Renzi tendrá que aprender para actuar en años sucesivos. Por eso también funciona como advertencia o lección irónica la comprobación de que a Viñas el éxito le hace "salir lo peor": "funciona mucho mejor cuando piensa como un perdedor" (Domingo 4 de junio, 1972; II, 304). literatura, que repercute directamente en la definición de la propia imagen de Renzi 
como escritor. Una de las primeras anotaciones al respecto es demoledora: "es mucho mejor él que sus textos" (Miércoles 16 [/diciembre/] 1964; I, 156) ${ }^{23}$. Si hay algo "insoportable" para Renzi en sus obras es "la reiteración del sentido de las acciones que se narran" (Domingo 15 [/enero/], 1967; I, 286), en lugar de trabajar la "sugestión", la "elipsis", el "no decir", un recurso esencial para Renzi, aprendido en Kafka y Hemingway. Viñas es la personificación de algo que Renzi sólo había encontrado en los libros:

Su incómoda - para él-e inauténtica dedicación a la literatura le da una suerte de hándicap, como si fuera un mártir que tiene derecho a todo, [...]. Veo ahí una actitud, por no decir una pose, que encuentro a menudo exhibida en los relatos que tienen como protagonista a un escritor imaginario. Veo entonces a David como un actor que hace de escritor y a la vez detesta esa figura [...]. (Lunes 14 [/septiembre/ ], 1970; II, 218)

Sin embargo, cuando describe la estrategia crítica de Viñas, Renzi parece anticipar las que él mismo desarrollará a partir de ese momento: "maneja con excesiva seguridad toda la historia de la literatura argentina", aunque "historiza un conjunto confuso de relaciones a las cuales les atribuye un sentido único" (Domingo 2 de agosto, 1970; II, 205); "Cuando habla de literatura es muy sagaz, busca su lugar y reconstruye continuamente la historia de la literatura argentina" ([Jueves] 1 de junio, 1972; II, 303). Renzi también hará de la búsqueda del lugar el objetivo de su actividad literaria, y la confrontación más sostenida en estos volúmenes que relatan su origen es con David Viñas, como si quisiera hacer justicia a un nombre o restañar un hueco en su genealogía $a^{24}$.

Se trata, no obstante, de una confrontación difícil, porque está teñida de afinidades: Viñas tiene "un modo de entender una realidad muy parecida a la mía (como ningún otro)", dice Renzi el jueves 18 de julio de 1968 (II, 45), pero unos meses más tarde confiesa actuar "defensivamente" con él "porque le cono[ce] las mañas" (Martes [24/septiembre/], 1968; II, 67). Enseguida, la afinidad parece excesiva ("se me parece demasiado"; Jueves 31 de octubre; II, 90), y al año siguiente se concreta en una visión agonística de la actividad literaria: "Como yo mismo, él nunca usa el impulso adquirido, las posibles "seguridades" adquiridas en sus libros anteriores, que son olvidadas en beneficio de la redacción competitiva. La rivalidad es la clave de su impulso" (Miércoles 17 [/diciembre/], 1969; II, 169). Poco a poco, empiezan a anotarse diferencias evidentes: "en el fondo le parezco "frío" y poco sincero, soy su mejor amigo, dice, y a la vez muestra una forma de ser excesivamente explícita y autocentrada- que es mi antítesis" (Martes 13 [/julio/], 1971; II, 258). Al año siguiente, una conversación aparentemente casual sobre los proyectos literarios de cada uno se envenena por el insoslayable afán competitivo de ambos y hace estallar la relación:

David me pregunta: "¿En qué andás?". Le doy una versión somnolienta del estado de la novela que estoy escribiendo y le digo que es probable que al final tire todo a la basura. "Sabés", me dice después de algunas vacilaciones, con aire conmovido, "sentí satisfacción desde el punto de vista competitivo al ver que tenés limitaciones, yo en cambio soy omnipotente". Vi todo rojo, y a partir de ahí, después de algunos cambios de palabras, le dije: "Mirá, viejo, dejemos las cosas aquí y hablemos dentro de diez años. Acordate de lo que estoy diciendo esta mañana y fijate entonces cómo estará cada uno de nosotros". Salimos cada uno por su lado y tuve la sensación de que la amistad con David estaba en peligro, por lo menos desde mí. (Lunes 19 de junio,1972; II, 308)

Renzi no soporta que aquel a quien considera su némesis pueda siquiera soñar en compararse con la magnitud de una aventura cuyos riesgos sólo él mismo parece capaz de aquilatar. El emplazamiento a reencontrarse una década después es un recurso 
melodramático y proyecta la escena, desde luego, al momento del triunfo de Respiración artificial, aunque ese eventual ajuste de cuentas queda ya fuera del decurso diacrónico de los Diarios (cerrado, justamente, en 1982). La ruptura, por otra parte, se produce el mismo año en que la redada en el apartamento de Renzi lo aboca a una vida semiclandestina, y su respuesta a Viñas parece implicar una ruptura total con el pasado y la decisión de seguir avanzando en soledad, liberado de un lastre que ya había temido unos pocos años antes, cuando había visto a Viñas así: "Doblado sobre sí mismo, soñando que está todavía en Europa, con miedo a la vejez y a repetirse como escritor, hablaba, sin encontrar las "aventuras" que pudieran entusiasmarlo. ¿No será ésa la imagen de mí mismo dentro de doce años?" (Domingo 6 [/julio/], 1969; I, 148).

\section{Renzi strikes back (y la aventura continúa)}

En la cronología particular de los Diarios, esos diez o doce años que comienzan con el temor de parecerse a Viñas y su ulterior ruptura, son los denominados "años felices" y "años de la peste". Todos, incluyendo los anteriores "años de formación", podrían considerarse "años de hostilidad", una tensión dialéctica que -casi inmediatamente después de la ruptura fundacional con Viñas- empieza a traducirse en términos de novela familiar (de nuevo, edípica), derribada ya la figura paterna, el avatar más definido del Escritor:

David me hace reproches varios, que es él quien viene siempre a buscarme, que me hago el duro, que lo juzgo desde arriba, etc. [...] David empieza a llorar, durante la discusión varias veces me llamó con el nombre de su hijo. Yo me siento pésimo, etc., etc. (Jueves 30 [/noviembre/] 1972; II, 323)

31 Pero aún faltaba un gesto del superhéroe literario que redondearía casi demasiado perfectamente ese relato edípico, esa aventura melodramática: Renzi, en la nouvelle epilogal ("Un día en la vida") que reorienta el proyecto de reescritura de los Diarios y ocupa el centro del volumen III, terminará casándose con la mujer de Viñas, Marta ("Beba") Eguía, alguien que había aparecido ya en aquel "retrato grupal" que lanzaba mi propia interpretación ${ }^{25}$. Culmina, así, una trama sentimental que venía desarrollándose desde hacía años, en la que Renzi reconocía el ejemplo de otra serie biográfica clave ${ }^{26}$, perfectamente integrada, al parecer, en esa contracultura cuyo final marcará también el de la formación del espíritu personal de Renzi y, por tanto, como se vio, el de sus Diarios ${ }^{27}$. El matrimonio es el símbolo de la domesticación ${ }^{28} \mathrm{y}$ la concesión al statu quo que Renzi está dispuesto a hacer para "borrarse del ambiente tóxico de la cultura argentina" (III, 222) e instalarse tranquilamente en Norteamérica. Pero desde mi perspectiva es también el remate simbólico de la operación de búsqueda del lugar: el héroe literario ya no es un novato; ha cumplido su objetivo, pero no se reconoce como parte del mundo en que se ha formado; así que decide quedarse con todo y recomponer su figura en otra parte.

Si los Diarios de Emilio Renzi de Piglia parecen, a veces, un "diario literario" -en la línea clásica del de los hermanos Goncourt-, en realidad lo que muestran es el trasfondo sobre el que la silueta del escritor habrá de trazarse con firmeza. En estas páginas he leído esos Diarios como una historia de afinidades y rivalidades concretas, como una especie de texto-tapiz donde el autorretrato y el retrato ajeno se traman y se borran recíprocamente, pero para hacerse una idea cabal de la magnitud de esta aventura literaria habría que atender aún a muchas otras cuestiones (la conciencia de extranjería y marginalidad del yo; su saberse vacío; su relación con otros "dobles" más familiares; la propia consideración del diario como un texto definido por la dialéctica entre elipsis y 
saturación...). Todo ello permanece confinado, por ahora, en un hueco, que alberga nuevas tentaciones y riesgos de lectura.

\section{BIBLIOGRAFÍA}

A.A.V.V., "Even Paranoiacs Have Real Enemies", Quote Investigator, 9 de julio 2016. Blog. Web. Consultado el 13/07/2018.

Arias Hernán y Eduardo Carrera, "De cómo se construye un escritor: los cuadernos de Piglia", Revista Anfibia, s.n., s.f. Web. Consultado el 13/07/2018.

Benjamin Walter, “Die Technik der Kritiker in dreizehn Thesen”, Einbahnstraße, Berlín, Rowohlt, 1928 , p. 35.

Dostoyevski Fiodor, Los demonios, Madrid, Alba Editorial, 2016. Traducción de Fernando Otero.

Fernández Cobo Raquel, "Los diarios de Ricardo Piglia: una lectura en busca de la experiencia perdida", Castilla. Estudios de Literatura nº 8, 2017, p. 62-97.

Gallego Cuiñas Ana, "Ricardo Piglia (con)forma su figura de autor: Los diarios de Emilio Renzi II", Í nsula $\mathrm{n}^{\mathrm{o}}$ 847-848, julio-agosto 2017, p. 45-48.

Piglia Ricardo, “Una lectura de Cosas concretas", Los Libros nº 6, diciembre 1969, p. 3.

--- "La ficción paranoica", Clarín, Suplemento "Cultura y nación”, 10 de octubre de 1991, p. 4-5. Desgrabación de Darío Weiner. Web. Consultado el 13/07/2018.

--- La Argentina en pedazos, Buenos Aires, Eds. de la Urraca, 1993.

--- Respiración artificial, Buenos Aires, Seix Barral, 1994.

--- Prisión perpetua, Madrid, Lengua de Trapo, 2000.

--- Crítica y ficción, Barcelona, Anagrama, 2001.

--- La ciudad ausente, Barcelona, Anagrama, 2003.

--- "La civilización Laiseca", Alberto Laiseca, Los Sorias, Buenos Aires, Gárgola, 2004, p. 7-10.

--- Por un relato futuro. Conversaciones con Juan José Saer, Barcelona, Anagrama, 2015.

--- Las tres vanguardias, Buenos Aires, Eterna Cadencia, 2016.

--- Los diarios de Emilio Renzi, 3 vols., Barcelona, Anagrama, 2015 (vol. I), 2016 (vol. II), 2017 (vol. III).

Premat Julio, Héroes sin atributos, Buenos Aires, F.C.E., 2008.

Trilling Lionel, The Opposing Self. Nine Essays in Criticism, Londres, Secker and Warburg, 1955. 


\section{NOTAS}

1. En lo que sigue identificaré las citas de los tres tomos de los Diarios con el número romano para el volumen y arábigo para la página. Precisaré la fecha de la anotación, poniendo entre corchetes el dato que no aparezca explícito en la obra (si ha podido deducirse).

2. No he podido localizar imágenes de ese cuadro. Hay una página de Facebook a nombre del pintor entrerriano Julio "Freddy" Martínez Howard (1932-1999) muy rica en reproducciones (consulta: 13/07/2018). Se pueden ver algunos datos biográficos del pintor y otras obras suyas en la web de la Galería Arroyo de Buenos Aires (consulta: 13/07/2018).

3. "En definitiva, si no hay nada más que los diarios, podrán ser vistos como el proyecto de alguien que primero decide ser escritor y luego empieza a escribir, antes que nada, una serie de cuadernos en los que registra su fidelidad a esa posición imaginaria" (Lunes 11 de septiembre, 1967; I, 323). Para la cuestión de la ficción y la figura de autor en el contexto pigliano, es muy interesante el trabajo de Premat (2008).

4. Es el título de la traducción de Alicia Bleiberg (Madrid, Taurus, 1974).

5. "[...] there is one distinguishing characteristic which seems to me pre-eminently important: its intense and adverse imagination of the culture in which it has its being" (Trilling 1955: X).

6. "Entonces decidió detenerse en ese primer ciclo que revelaba mejor que nada la verdad de su destino, que hacía ver su proyecto de convertirse en un buen escritor; le había llevado veinticinco años encontrar una salida, una puerta estrecha por donde pasaba, por decirlo así, el sentido" (III, 161). Y prosigue: “[...] luego su vida era demasiado pública, de modo que lo que en sus diarios había registrado no era pertinente incluirlo en esta versión de su experiencia. Me detuve en 1982 porque hasta ahí no había abdicado ni me había suicidado, y luego, como el profeta Isaías, confundiría los años con los días, una jornada entera que encerrara, en sus horas, varios tiempos" (III, 162).

7. El consejo paterno es una frase cuya paternidad está en discusión: se atribuye también a Kissinger, a Golda Meir o incluso en algún lugar a Woody Allen (AA.VV. 2016 Web).

8. “[...] Nunca sabré si era a mí a quien el ejército estaba buscando, pero tuve que actuar en consecuencia, como si efectivamente yo, un pacífico y conflictuado aspirante a escritor, fuera un revolucionario peligroso. Ese malentendido, ese cruce, me cambió la vida" (II, 10).

9. Hay que recordar ahora al "agente secreto", protagonista de la novela de Conrad del mismo título, que tendrá una función esencial en la última novela de Piglia (El camino de Ida). El modelo que evoca explícitamente Piglia es teórico y recurrente: la interpretación que hace Benjamin de Baudelaire "como un espía en territorio enemigo" (Lunes 14 [/septiembre/], 1970; II, 218).

10. "Anoche una llamada de Marcelo Pichon-Rivière que alude al grupo ligado a la revista Vigencia y a la editorial de la lamentable Universidad de Belgrano, que me tiene como su enemigo ideal. Quieren sacarme del medio pero no lo lograrán, dijo, más allá de las heridas que produce el combate" (Viernes 14 [/agosto/], 1981; III, 149).

11. Es, en parte, la tesis de Premat (2008: 203-236), quien ya vio -antes de conocer su forma finalque el diario era "el eslabón más complejo en la construcción de ese personaje" (205).

12. Es el inicio del capítulo I.3 de la primera parte de Los demonios.

13. Lo ha visto bien Gallego Cuiñas (2017) y ha explorado con algo más de detalle empírico la relación con revistas y editoriales Fernández Cobo (2017).

14. Ese ejercicio de ordenación sólo se produce, de hecho, en el volumen II. La "serie A" es "la de los acontecimientos políticos que actúan directamente sobre la esfera íntima de mi existir" (II, 11); la "serie C" incluiría la "relación con las chicas" (II, 12), pero a veces se cruzaría con la serie B; la "serie E" se refiere a lo que podríamos llamar consideraciones metadiarísticas (o escritura 
autoconsciente); la "serie X" recoge los contactos con la lucha armada. Hay una breve serie Z, referida al parecer a algunas alucinaciones.

15. Otra característica de la conciencia paranoica, que reproduce, por ejemplo, el Junior de La ciudad ausente (también, en este sentido, quizás, relato de "serie B"): “Todos parecían vivir en mundos paralelos, sin conexión. "La única conexión soy yo", pensó Junior" (Piglia 2003: 14).

16. Además de las opiniones sobre Vargas Llosa y Fuentes, convendría analizar las referencias a Cortázar y a Onetti, sobre todo, y no olvidar un proyecto de Crónicas de Latinoamérica para el que parece haber escrito incluso un prólogo (Jueves 12 [/marzo/], 1967, I, 296; 23 de abril, 1967, I, 307; 8 de mayo, 1967, I, 309). Hay también una anécdota significativa con García Márquez, que se inicia en términos pugilísticos ("Me lo presentó Rodolfo Walsh, que jugó el jueguito competitivo, a la Hemingway, y me anunció como una promesa del box nacional, como si yo fuera un peso wélter con mucho futuro y con la misión secreta de derrotar a los campeones de la categoría, entre ellos García Márquez y el mismo Walsh") y se cierra con célebre injuria borgiana: "Sobre la novela de García Márquez parece que Borges, que siempre está al tanto de todo, le dijo a Enrique Pezzoni: "Es buena, pero le sobran cincuenta años"" (Lunes 4 de septiembre, 1967; I, 322).

17. Ese modelo "paternalista" se reproducirá implícitamente en la presentación de un joven Alan Pauls: “[...] es muy inteligente y escribe muy bien. Tengo con él la misma sensación que tuve cuando leí las primeras cosas de Miguel Briante, que también a esa edad mostraba gran destreza y un estilo notable. Sin embargo me parece que Alan Pauls tiene mayor futuro, Miguel terminó enredado en el mito del escritor precoz y le costaba mucho volver a escribir. Alan, en cambio, es o intenta ser, me parece a mí- más completo, más culto, y se puede esperar de él lo mejor" (Jueves 1 de diciembre, 1977; III, 55). El propio Pauls ha traducido su relación en código edípico: “ Había leído Nombre falso en las vacaciones del 75 y había quedado completamente hechizado por el libro, así que vía Josefina [Ludmer] conseguí encontrarme con Ricardo y pasarle algunos de esos textos. Muy pronto se organizó una especie de academia familiar: la madre China [Ludmer] era la teoría, el padre Ricardo la ficción (y todos los híbridos posibles), yo, el discípulo más privilegiado del mundo" (en Arias y Carrera, s.f.).

18. No es casual que sea uno de los nombres clave de sus clases dedicadas a las "tres vanguardias" en 1990 (Piglia 2016). Los otros dos son Walsh y Saer: con el primero, Renzi sólo expone en los Diarios una "velada y caballeresca competencia" ([Martes] 1 de abril, 1969; II, 131), que afecta a la relación entre política y literatura. Con Saer, no parece haber competencia de ningún tipo. La idea de esas clases ya se expone en una nota del 13 de junio de 1968 (II, 36).

19. “Marconi sí está lejanamente inspirado en Osvaldo Lamborghini” (Viernes 25 [/enero/], 1980; III, 109): es el poeta de Respiración artificial, con el que el Renzi de la novela mantiene su famosa "payada intelectual".

20. El enfrentamiento con la revista Vigencia, a la que se califica de "revista de cultura oficial [...] que trabaja para el nuevo consenso del general Viola" (Miércoles 5 [/agosto/], 1981; III, 145) será un motivo recurrente en esas fechas y pretexto para incluir la única mención (difusa) a César Aira en los Diarios: "[...] la barra de la Editorial de Belgrano trata de borrar a los escritores que han escrito acá y ellos se postulan como la nueva cultura -cínica y paródica- surgida de los años de la peste (el objetivo soy yo, recordar la charla con O. L. en la terminal). En una entrevista Cesar [sic] A. dijo que yo tenía cara de policía. Desde luego son tonterías, acusaciones, maniobras costumbristas de la literatura vigilante [...]" (Jueves 6 [/agosto/], 1981; III, 146). La tensión es notable, porque propicia uno de los pasajes del Diario en los que Renzi define con más claridad su posición en términos de la Literaturkampf benjaminiana: "Enfrentado con los "vanguardistas" de la editorial de la Universidad de Belgrano (!) y con los "realistas" onda Centro Editor, me muevo en un territorio inestable pero mantengo la guerra de posiciones y el campo propio. Aparecen dos sistemas que yo sintetizaría en las oposiciones públicas y periodísticas. Desde luego no soy yo 
quien publicita esos combates, no tengo nada que ver con la invención de rivalidades que no propongo ni me interesa. La cuestión es siempre la misma. ¿Qué tipo de gente es capaz de resistir la presión social y en qué momento? Mantener el estilo en medio del combate, elegancia bajo presión" (Viernes 7 de agosto, 1981; III, 146-147).

21. Desde luego, hay presencias bien identificadas que no se definen tan claramente como antagonistas y por eso quedan fuera de esta reconstrucción: Andrés Rivera, Germán García, Nicolás Rosa, Enrique Pezzoni, Jorge Álvarez, Luis Gusmán, Rodolfo Rabanal, Óscar Masotta...Ni siquiera Carlos Altamirano, a pesar de notables desacuerdos políticos en algún momento, se presenta como rival. Por el contrario, en Alberto Laiseca, Renzi reconoce la misma conciencia de amenaza que él padece, "pero por otros motivos, esotéricos e íntimos" (Martes 10 [/enero/] 1978; III, 65), como si ocupara un margen no coyuntural (definido por la política) y así personificara con más derecho la utopía literaria a la que Renzi aspira. Piglia prologará su monumental novela Los Sorias en 1998, y afirma que es "la mejor novela que se ha escrito en la Argentina después de Los siete locos" (Piglia 2004).

22. A principios de los setenta hay, por ejemplo, dos Juanes, cuyo apellido se reduce a una inicial -quizá falsa- que parecen representar dos arquetipos de escritor, que Renzi podría estar queriendo evitar o -tal vez- fusionar: por un lado, Juan M. (Lunes 3 [/mayo/], 1971; II, 245), el escritor de "obstinada voluntad", al margen de la difusión de su obra; por otro, un Juan Ñ que "como intelectual, es mi antítesis, pertenece a la especie de los que empiezan por asegurarse su lugar social y subordinan el pensamiento a esa posición" (Lunes 10 [/enero/], 1972; II, 287).

23. Una década después repite y amplía la idea: “Él es mucho mejor que sus libros: cuando escribe usa una retórica áspera, una sintaxis esquemática; cuando habla cara a cara, lo que dice parece una confesión, siempre demasiado sincera y arriesgada [...]" (Lunes, 1973; II, 337).

24. Salvo error, la presencia de Viñas en la escritura crítica de Piglia se reduce a una reseña de Cosas concretas, en 1969, y a las dos páginas que le dedica en La Argentina en pedazos (1993). El resto son apariciones muy ocasionales. La publicación de las conversaciones con Juan José Saer permitió, no obstante, recuperar un párrafo muy significativo de 1999: "Walsh puso a las novelas de Viñas en el freezer. [...] Entre Arlt y Borges, entre Walsh y Viñas - para hacer oposiciones que nos permitan abrir este campo -, algunos de nosotros hemos intentado mantener una relación que diera cuenta de estas discusiones sin que eso suponga hacerse cargo de políticas duras en términos de literatura ni subordinar la escritura literaria a las exigencias morales de posiciones políticas circunstanciales o más o menos circunstanciales" ("Literatura y política hoy"; Piglia 2015: 106).

25. A pesar de que en los Diarios siempre se da su nombre, aquí se transforma en Carola: "Se había casado porque se había enamorado de Carola, a la que conocía y deseaba desde hacía años pero con la que había mantenido una amistad platónica porque ella era, en ese tiempo, la mujer, la compañera, como se decía entonces, de su amigo David y él estaba decidido a no volver a repetir sus andanzas del pasado y a no volver a caer en un triángulo adúltero, así que empezó a salir, como se dice, con Carola cuando ella ya se había separado de su evidente compañero, el intenso, hermético y combativo D.V." (“Un día en la vida”; III, 222-223).

26. "La política, la literatura y los amores envenenados con la mujer de otro han sido lo único verdaderamente persistente en mi vida" ("En el estudio"; I, 127). Los episodios de esa trama sentimental específica que los Diarios recogen son numerosos, y no pueden comentarse aquí. Pueden verse las entradas del 9 de agosto, 1968 (I, 47), del 5 de julio, 1974 (II, 359) o de un lunes de septiembre de 1975 (III, 410).

27. Conviene recordar que Piglia, en la reseña de Cosas concretas, había escrito sobre los protagonistas de la novela de Viñas: "Los hombres se hablan a través de las mujeres y el lugar de este encuentro es el coito con una mujer que han "conocido" todos: espacio privilegiado, en ese 
cuerpo familiar el relato común se organiza y actúa" (Piglia 1969). Y en los Diarios comenta Renzi: "Los amigos y yo mismo sólo miramos a las mujeres de la tribu y circulamos entre ellas como el naipe de una baraja marcada, nadie se puede quejar porque todos hacemos lo mismo. [...] Endogamia y pasiones circulares" (Lunes 7 [/octubre/], 1974; II, 377).

28. Y los términos irónicos que utilizan sus amigos para comentar la decisión son idénticos a los que Renzi ha usado para criticar a los intelectuales tras el fin de la dictadura: "Emilio había vuelto al redil" (III, 222).

\section{RESÚMENES}

En las páginas que siguen se leen Los diarios de Emilio Renzi como un cuaderno de batalla o agenda de combate literario. Se exploran algunos lugares en los que el sujeto busca definirse como autor mediante el antagonismo y la rivalidad con otros escritores, alguno de los cuales (singularmente, David Viñas) parece cobrar el valor de némesis, un contrincante que se le parece, que viene del pasado, y al que debe superar para llegar a cumplir su misión y conocer su identidad.

Dans les pages suivantes, on lit Los diarios de Emilio Renzi en tant que carnet de combat littéraire. On explore quelques passages dans lesquels le sujet essaie de se définir comme auteur dans l'antagonisme et la rivalité envers d'autres écrivains. Parmi ceux-ci, il y en a qui semblent jouer le rôle de némésis : c'est le cas de David Viñas, un opposant qui ressemble au protagoniste, qui vient de son passé et qui doit être vaincu afin que le héros accomplisse sa mission et arrive à connaitre son identité.

In the next pages Los diarios de Emilio Renzi are presented as a notebook of literary battles. Passages shall be explored, where the main character tries to define himself as an author by showing his antagonism and rivalry towards other writers. Some of these writers (particularly David Viñas) seem to play the role of a nemesis: an enemy that resembles the protagonist, that comes from his past and who must be overcome if the hero wants to accomplish his mission and know his identity.

\section{ÍNDICE}

Mots-clés: journaux intimes, récit de formation, image d'écrivain, lutte littéraire, écrivains argentins.

Keywords: diaries, story of a formation, writer's image, literary battle, Argentinian writers.

Palabras claves: diarios, relato de formación, imagen de escritor, lucha literaria, escritores argentinos.

\section{AUTOR}

\section{DANIEL MESA GANCEDO}

Universidad de Zaragoza

danmesa@unizar.es 